\title{
ANDROID BASED FLAT SECURITY SYSTEM - THE DIGITAL UNLOCKING AND LOCKING SYSTEM BASED ON ANDROID FOR SMART PHONE
}

\author{
Abhishek Dhar Dwivedi \\ Department of CSE \\ IMS EC, Ghaziabad, U.P., India \\ Siddhant Tomar \\ Department Of CSE \\ IMS EC, Ghaziabad, U.P., India
}

\author{
Himalaya Gupta \\ Department Of CSE \\ IMS EC, Ghaziabad, U.P., India \\ Deepak Jaiswal \\ Department Of CSE \\ IMS EC, Ghaziabad, U.P., India
}

\begin{abstract}
In this paper, we propose a flat security system for society. the foremost objective of this method is to offer an ingenious answer to beat challenges. Prototype supports manual control and microcontroller control to lock and unlock the door of the house. The door lock system here is essentially designed for normal mode and multi mode operations. The proposed task is to transmit the signal from the mobile to the receiver using the Wi-Fi system. The Wi-Fi range allows the user to lock and unlock any system or appliance from inside or outside the house. the most purpose of the work is that if the door isn't locked, the user can lock the door from his / her smart phone via Wi-Fi range, which saves the person energy and saves time. Smart locks can grant or deny access remotely via a mobile app. Such a system is important during a bank and commercial enterprise. The system also provides functionality for the overall user, where the only user lock is permitted to work. The goal of the system is to develop a real-time face recognition model with low cost solutions in security.
\end{abstract}

\section{INTRODUCTION}

Facial recognition are often a difficult diagnostic space in pattern recognition thanks to differences in facial expressions, postures, and brightness. A growing number of applications, from implementation to industrial work, require commerce to develop financial and automatic face recognition systems. to stop theft and identity fraud, a face recognition system must be established. The goal of this project is to develop a security management application supported by face recognition. Hor-like cascade properties are used for face recognition and therefore the LBPH rule is employed for face recognition. We use OpenCV libraries and Python computer-based language to realize accuracy and effectiveness.
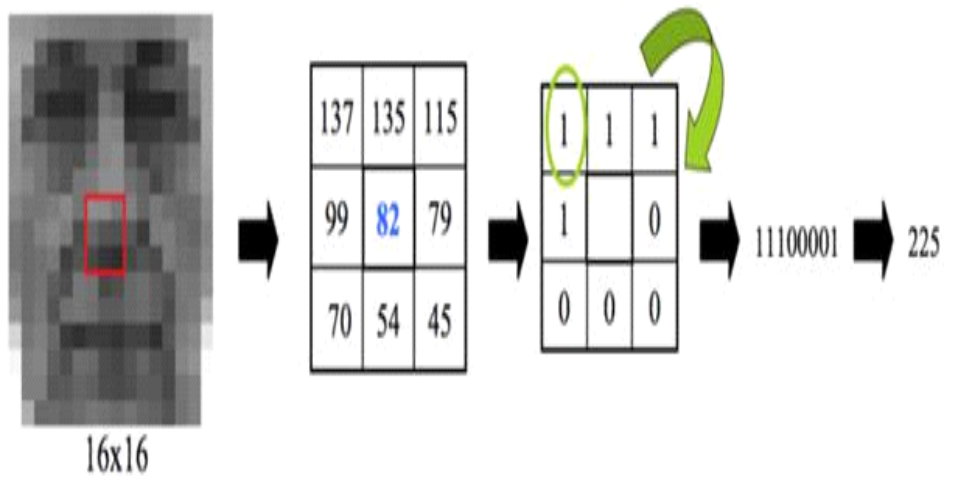

Fig.1

Face recognition has conjointly proved helpful in several transmission science areas. biometric identification analyze the characteristic of face pictures input from a digital video camera or on-line face capturing. Currently we would like to take care of security in each organization and every individual must enhance their security system. Door lock system became a typical feature on many various sorts of buildings and houses. they are getting popular a day to develop an efficient electronic devices which give security. Home security has been a serious issue due to the rise in rate and everybody wants to require proper action to stop unauthorized user. There was a necessity to automate home in order that user can cash in of the GSM technology and computer system. The devices sort of a telephone land line or the worldwide System of Mobile communication (GSM) can provide features which may be used domestically to handle appliances like; door, television, robotic arm, refrigerator, air condition, electric bulb, etc. There 


\section{International Journal of Engineering Applied Sciences and Technology, 2020 Vol. 5, Issue 2, ISSN No. 2455-2143, Pages 192-196 \\ Published Online June 2020 in IJEAST (http://www.ijeast.com)}

are certain situations which are very annoying like when a person locks himself out of his house or office or he leaves his key inside or sometimes when a thief just breaks the lock and steals everything. These kinds of situations always trouble people that use manual door lock with keys. Although in some places people use smart cards, there might arise a situation when someone loses the cardboard or keeps the cardboard inside. Then in other scenarios there are caretakers for locking houses or offices and keeping the keys safe. Our design is implemented to supply better securities as users don't got to remember passwords and don't need any kind of keys or cards that always stray. If someone's face is permitted in the system he/she wouldn't face any sort of delays to enter an area. Face recognition is one among the foremost secure systems because a face of 1 person never matches with others. Therefore unauthorized access are often restricted by designing a lock that stores the faces of one or more authorized users and unlock the system when a match is found. most of the individuals would really like higher security system which supplies complete security solution. This makes face a singular identification for everyone. The popularity and reliability on face scanner are often easily guessed from its use in recent handheld devices like mobile phones and laptops.

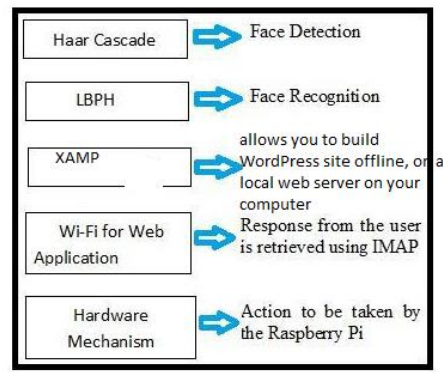

\section{SYSTEM ARCHITECTURE}

It is necessary to incorporate software and hardware components to develop a face recognition system. This section discusses the implementation stack needed to create the system as shown within the figure. The stack includes the hardware component along side the software. Face detection and phase recognition show the Har cascade, LBPH, respectively. Wi-Fi is employed for wireless communication between the system and therefore the user. The last section provides an outline of the hardware components used.

\section{[a]. Face Detection}

In this paper we've used the Har Cascade classifier to differentiate the face from the real-time image taken using the camera. The Har Cascade classifier exploits the Haar features to extract the face from a real-time image. Once the face is identified, the pixel locations are identified. These pixel positions are often wont to resize the image in order that it only features a face part and that we ignore other unwanted information from the real-time image. This resized image is stored within the database as a label with an individual's name. We used 50 facial images from each individual as a database for our training algorithm. The figure shows the database of the one that stored it. The camera detects the person's face and only captures the image of the face.

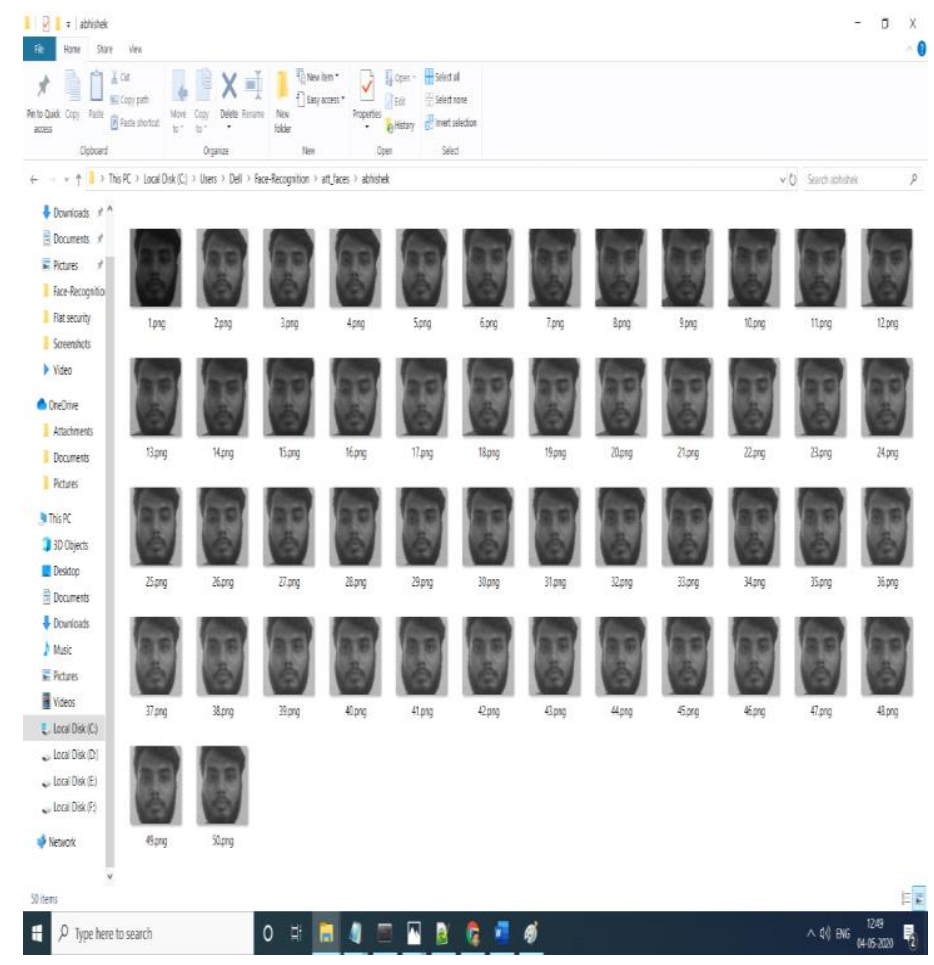

Fig. 2.1

\section{[b]. Face Recognition}

In this paper we've used an area binary sample histogram for training and identification purpose. The database created using the Har Cas-CADE classifier is employed here for training purposes. LBPH divides the image into smaller windows. It calculates the

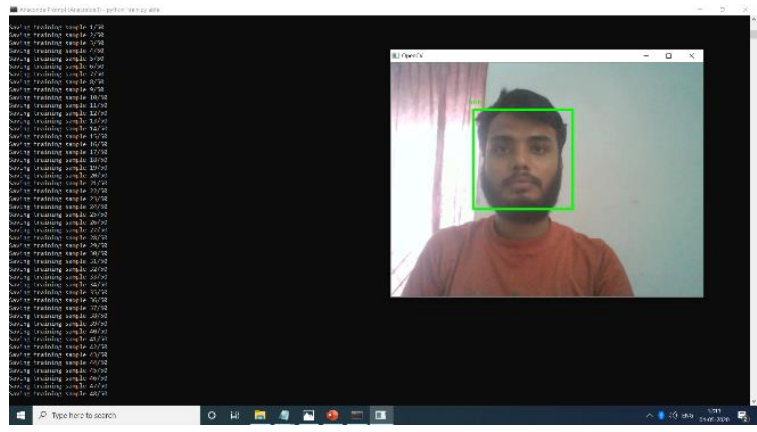

Fig.2.2

new value for the central pixel of the window using the local threshold value because the central pixel value. After computing the LBP, we get a replacement image, which has good features, then 
the first image. Now this LBP image is split into multiple grids. The histogram is calculated for every grid and forms one histogram called the LBPH of the image. For face recognition, the LBPH of the realtime image is calculated then compared with the LBPH of the pictures with the database. Fig. 2.1 shows that the camera detects the face of the person and identifies it with the stored database and locates the right face with the label and value.

\section{[c]. Android Programming}

Android software development means new applications are created for devices running the Android OS. Mobile devices like tablet computers, notebooks, smartphones, electronic book readers, set-top boxes, etc.It includes a Linux based OS, middleware and key mobile applications. That is, it connects the hardware to the software and provides the standard services. But quite that, it is a mobilespecific operating system: an OS designed to figure on mobile. Google released the primary beta version of the Android Software Development Kit (SDK) in 2007, where the primary commercial version, Android 1.0, was released in September 2008. Google announced subsequent Android version 4.1 jelly egg at the Google I / O conference on June 27, 2012. jelly egg is an incremental upgrade, with the first goal of improving the interface, both in terms of functionality and performance. it's the most important installed base of any mobile platform and is growing rapidly. quite 1 million new Android devices are activated worldwide a day.

\section{[d]. Blueprint of Application}

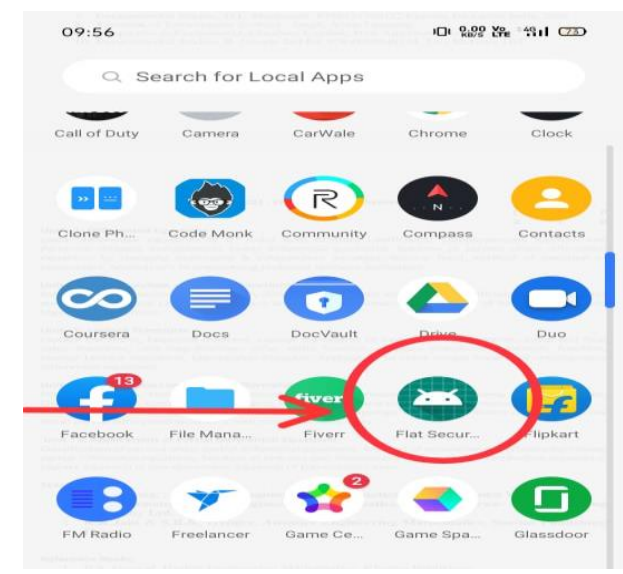

Fig.2.3

\section{[e]. Home Screen of Application:}

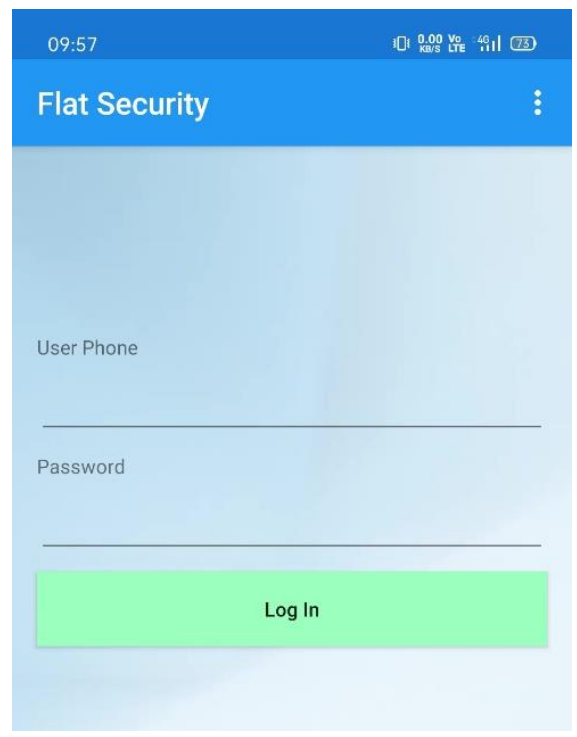

Fig.2.4
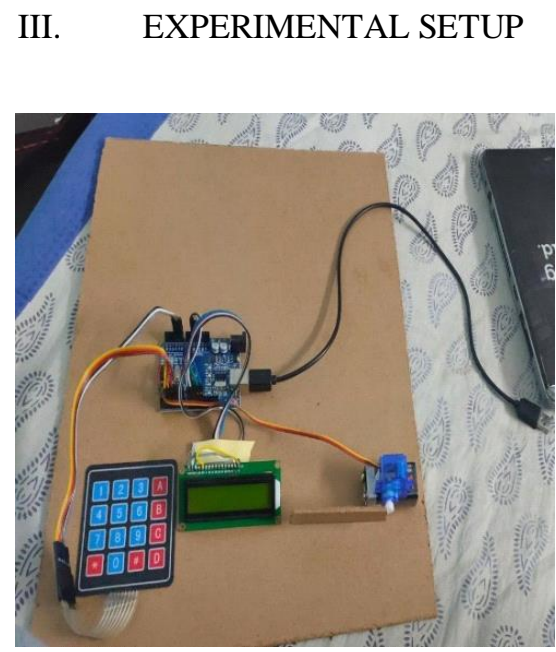

Fig.3.1 System Setup

We start with system and other components attached thereto as show in Fig. The camera is sited to capture the image.

\section{[i]. Arduino Uno}

Arduino Uno is an open source microcontroller board supported the Microchip ATmega328P Microcontroller and developed by Arduino.cc. The board consists of a group of digital and analog input / output ( I / O) pins that are connected to varied expansion boards (shields) and other circuits. 


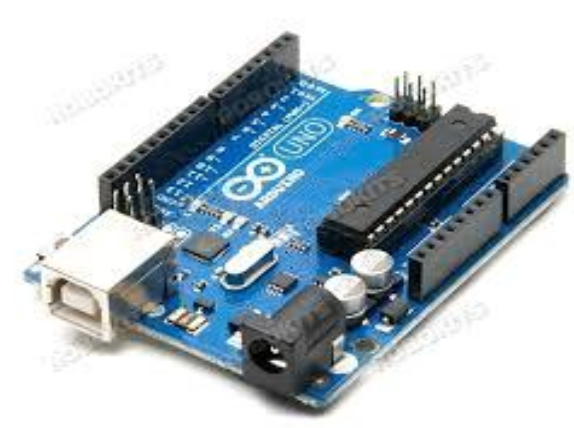

Fig. 3.2

\section{[ii]. Servo Motor}

A servo motor is an device that pushes or rotates an object with great accuracy. If you would like to rotate and object at a particular angle or distance, you employ the servo motor. it's made from an easy motor driven by a servo mechanism.

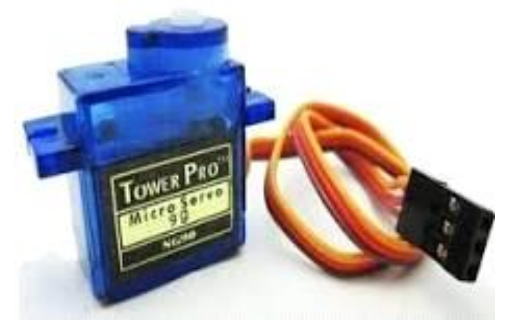

Fig.3.3

\section{[iii]. LCD Screen}

Liquid crystal display technology works by blocking light. Specifically, an LCD polarized glass is formed from two pieces (also called substrates) with liquid crystalline material between them. The backlight creates the sunshine that passes through the primary surface.

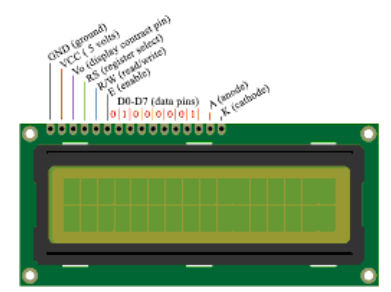

Fig.3.4

\section{[iv]. Keypad}

The keypad is one among the foremost commonly used input devices in microprocessor applications. On a typical keypad wired as an X-Y switch matrix, normally open switches hook up with the column when pressed. If the keypad has 12 keys, it are often wired by 4 rows into 3 columns. The 16-key pad contains 4 columns of 4 columns.

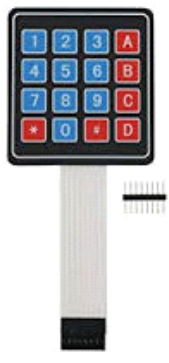

Fig.3.5

\section{FUTURE SCOPE}

A chargeable battery are often provided which may provide power backup just in case of power outage. The GPS and GSM system are often used if someone tries to hack the lock password or cause any physical damage. The GPS and GSM system also tracks the situation of the thief and our location, sending an alert message about an attack on our smart-lock. It also can be implemented using cloud computing, where the user can control the lock no matter its location. For more security, a finger scanner are often used. Voice also can be communicated with the person on the opposite side of the door, to avoid opening the door whenever. This system also can be installed with a fireplace alarm. Usually we do not have fire alarms within the house, so this technique works on both lock and fire alarms. this technique are often used as an alternate lock for extra security in hotels, banks or anywhere else.

\section{CONCLUSION}

This paper implements an economical powerful computer system for face recognition. the supply of OpenCV proves to be beneficial for building a face recognition system at the local level. the facility provided to the user by mail plays a crucial role. the utilization of the LBPH algorithm for face recognition works well for the database to possess clear images. The more variations of face training data the system has, the higher the face recognition and fewer chance of naming the face from the available database. the utilization of the OpenCV library proves to be very effective for face recognition and face recognition. The paper shows the mixing of the OpenSV library with the system camera wont to create Android applications.

\section{ACKNOWLEDGEMENTS}

We would wish to thank to the staff of Department of computing \& Enginnering for his or her encouragement and support. 


\section{International Journal of Engineering Applied Sciences and Technology, 2020 Vol. 5, Issue 2, ISSN No. 2455-2143, Pages 192-196 \\ Published Online June 2020 in IJEAST (http://www.ijeast.com)}

\section{REFERENCES}

1. Wazwaz, A. A., Herbawi, A. O., Teeti, M. J., and Hmeed, S. Y. (2018). Raspberry Pi and PCs based face discovery and acknowledgment framework, 2018 fourth International Conference on Computer and Technology Applications (ICCTA), Istanbul, pp.

171-174.

2. Sánchez López, Laura.( 2010). Nearby Binary Patterns applied to Face Detection and Recognition. Spanyol: Universitat Politecnica De Catalunya.

3. Gupta, I., Patil, V., Kadam, C., and Dumbre, S. (2016). Face discovery and acknowledgment utilizing Raspberry Pi, 2016 IEEE International WIE Conference on Electrical and Computer Engineering (WIECONECE), Pune, pp. 83-86.

4. Chen, W., Er, M. J., and Wu, S. (2005). \{PCA $\}$ and $\{\mathrm{LDA}\}$ in $\{\mathrm{DCT}\}$ space, Pattern Recognition Letters, vol. 26, no. 15, pp. 2474-2482. Sunehra, D., and Veena, M. (2015). Execution of intuitive homes computerization frameworks dependent on email and Bluetooth advancements, 2015 International Conference on Information Processing (ICIP), Pune, pp.

458-463.

5. Gargenta M. what's more, Nakamura M. (2014). Learning Android: Develop Mobile Apps Using Java and Eclipse. second Ed. O'Reilly. USA

6. R. John Robles and Tai-hoon Kim, (2010). Applications,Systems and Methods in Smart Home Technology: AReview, International Journal of Advanced Science andTechnology. 15: 37-48.

7. Julius Bin Pelipos,(2010). "Shrewd Key Door with Wireless Security System utilizing RF Signal," Faculty of Electrical and Electronic Engineering, UniversitiTun Hussein Onn Malaysia: Final Year Project Report, 2010.

8.NeelamMajgaonkar,RuhinaHodekar,PriyankaBan dagale,(2013)."Automatic Door Locking System",
International Journal of Engineering Development and Research, Volume 4, Issue 1, ISSN: 2321-9939.

9. Sedhumadhavan. S1, Saraladevi. B2 .(2014)." Optimized Locking and Unlocking a SystemUsing Arduino", International Journal of Innovative Research in Computer and Communication Engineering (An ISO 3297: 2007 Certified Organization) Vol. 2, Issue 11.

10 .Kamelia L., Alfin Noorhassan S.R, Mada Sanjaya And W.S., Edi Mulyana.(2014). ,"DoorAutomation System Using Bluetooth-Based Android For Mobile Phone", Vol. 9, No. 10, Issn 1819-6608 Arpn Journal Of Engineering and Applied

Sciences.

11. Ramlee R.A., Tang D. H. Z., Ismail M.M., (2012)"Smart Home System for Disabled People Via Wireless Bluetooth", in Proc. of IEEE International Conference on System Engineering and Technology, pp. 1-4.

12. Mishra Arpita, Sharma Siddharth, Dubey Sachin, Dubey S.K.(2011).,"Password Based Security Lock System", International Journal of Advanced Technology in Engineering and Science.

13. Hassan Harnani, Bakar Raudah Abu, Ahmad Thaqib and FawwazMokhtar, (2012)"Face Recognition Based on AutoSwitching Magnetic Door Lock System using Microcontroller" in International Conference on System Engineering and Technology, Indonesia.

14. MohamadIsah JulisahBinti,(2009)."Main Door Security System using SMS." Faculty of Electrical and Electronic Engineering, Universiti TunHussein Onn Malaysia: Final Year Project Report. 